\title{
Short-term and long-term unintended impacts of a pilot reform on Beijing's zero markup drug policy: a propensity score- matched study
}

\author{
Jianying Zeng ${ }^{1}$, Xiwen Chen ${ }^{1}$, Hongqiao Fu' ${ }^{1}$ Ming $\mathrm{Lu}^{2}$ and Weiyan Jian ${ }^{1 *}$
}

\begin{abstract}
Background: In September 2012, Beijing, the capital of China, selected five tertiary hospitals as pilots to remove the previously allowed 15\% markup for drug sales. However, while most research demonstrated the significant decrease in drug sales, the core issue of high health expenditure was not well solved because of the unintended policy impact. This study aimed to empirically evaluate the short-term and long-term unintended impacts on controlling medical expenses of Beijing's zero markup drug policy from 2012 to 2015.

Methods: This study extracted 2012-2015 individual-level data from the Beijing Urban Employee Basic Medical Insurance (UEBMI) database and performed a propensity score-matched analysis to evaluate the short-term and long-term impacts on controlling medical expenses. All inpatients in the 5 pilot reform hospitals were selected as the intervention group, while inpatients in other tertiary hospitals were selected as the control group.

Results: A total of 520,996 inpatients were extracted in this study. For patients in the pilot hospitals, the total expenditures per admission decreased from 17,140.3 yuan in 2012 to 15,430.1 yuan in 2013 and then increased to 16,789.8 yuan in 2015. Expenditure on drugs reduced from 5811.7 yuan in 2012 to 3903.4 yuan in 2015. However, a significant substitution effect of medical consumables was first observed in the third quarter of 2014, which undermined the impact of the policy. In the long-term, the intervention group and control group demonstrated the same trend.

Conclusions: After the zero markup drug policy, expenditure on drugs revealed a continuous decline. However, the decline in total expenditure was weakened by the substitution effect of medical consumables in the long term.
\end{abstract}

Keywords: Healthcare expenditure, Healthcare reform, Cost containment

\section{Background}

Over-prescription of expensive pharmaceuticals has become a global concern for increasing total health expenditure $(1,2)$. Many countries have implemented several policies in order to reduce drug prices and control the total growth of health expenditures. Recently, in OECD countries, drug expenditure, on average, accounted for approximately $20 \%$ of total health expenditure. In France, the cost of drugs also accounted for

\footnotetext{
* Correspondence: jianweiyan@bjmu.edu.cn

${ }^{1}$ Department of Health Policy and Management, School of Public Health,

Peking University Health Science Center, Beijing, China

Full list of author information is available at the end of the article
}

$17.5 \%$ of total health expenditure, while in the United States, it accounted for approximately $10 \%(3-5)$. However, compared to developed countries, China must address the greater problem of the widespread overprescription of drugs caused by a $15 \%$ markup policy for drug sales (6). Hospitals in China can make profits from drug sales, which is one of the three main channels for the income of public hospitals. The other two income channels are medical service charges and government financial subsidies (7). Moreover, with the reductions in the government's financial subsidies and restrictions on the price of medical services, drug expenditure has been growing and accounted for $30-40 \%$ of the total health

(c) The Author(s). 2019 Open Access This article is distributed under the terms of the Creative Commons Attribution 4.0 International License (http://creativecommons.org/licenses/by/4.0/), which permits unrestricted use, distribution, and 
expenditure in the 2000s $(8,9)$. Meanwhile, researchers have noted that the incentives from the $15 \%$ markup policy for drug sales have prompted doctors to prescribe large amounts of unnecessary antibiotics, injections and hormones such as the steroid drugs, which has become a major problem in China's public health field (10-12).

China has begun to eliminate drug markups in the last decade but had to face the complex compensation mechanism in public hospitals $(13,14)$. Public hospitals in China are the dominant provider in the Chinese health system and treat more than $80 \%$ of inpatients (15). The Chinese government therefore tried to remove the previous $15 \%$ markup for drug sales at public hospitals and replaced it with the zero-markup drug policy, hoping that public hospitals could no longer make a profit from selling drugs and, predictably, irrational drug use would be reduced. In September 2012, Beijing, the capital of China, selected five tertiary hospitals as pilots to remove the previously allowed $15 \%$ markup for drug sales and implement the zero markup drug policy. And after that, the State Council of China announced that all urban public hospitals must implement the zero markup drug policy by September 2017. While most research demonstrated the significant decrease in drug sales, the core issue of high health expenditure, however, was not well solved because of the unintended policy impact. The unintended outcome of medical consumables would be even worse if the hospitals treated more inpatients and faced more administrative challenges (16), which reignited the debate about eliminating drug markups.

To date, studies on the unintended impact of the zero markup drug policy were mostly aggregated in the substitution effect of medical consumables and diagnostic tests (17), but their results were varied $(18,19)$. One study that analysed county-level public hospitals in Shandong province in China noted that no expenditure transfer from drugs to medical consumables or diagnostic tests was observed due to the removal of drug markups (20) while others presented the opposite case. Moreover, their reforms were multiple and complex which included not only one drug policy but varied internal reforms in hospitals. In addition, the substitution effect were less likely observed with only short-term analysis such as interrupted time series analysis because providers' behaviours also need time to change. Thanksfully, there did exist one single reform of drug policy if back to the first pilot reform in Beijing which reformed five tertiary hospitals while other tertiary hospitals implemented the previous drug policy, providing a chance of long-term comparison.

This study aimed to evaluate the short-term and longterm impacts on medical expenses of Beijing's zero markup drug policy from 2012 to 2015 . We hypothesize that, compared with hospitals in the control group, the total expenditure of pilot hospitals would decrease in short-term thanks to the decline in drug sale but would gradually rise due to the increase of the expenditures on medical consumables and diagnostic tests.

\section{Methods}

\section{Study design and participants}

This study extracted four years of individual-level data from the Beijing Urban Employee Basic Medical Insurance (UEBMI) database, which has collected all inpatient medical records in Beijing public hospitals. The inpatient medical records in this study are age, gender, admission time, the main diagnosis and its ICD coding, the secondary diagnosis and its ICD coding, total hospital expenditures and the expenditure breakdown. Based on Chinese government documents and UEBMI database, hospital expenditures fall into six categories: drugs, medical services, medical consumables, diagnostic tests, nursing services and management services. Descriptions of the basic characteristics for each year and the top 10 diagnoses are listed in Table 1. All expenditure variables are converted to 2012 using the Consumer Price Index (see in the Appendix 1).

In this study, we selected all UEBMI inpatients from January 1st, 2012 to December 31st, 2015 in Beijing. In September 2012, Beijing started the single drug policy reform and at the end of 2012, all pilot hospitals accomplished zero markup drug reform. From 2016 to 2017, Beijing implemented more complex health reforms which shocked the existing medical expenses and made it hard to follow up.

Overall, a total of 1,521,659 cases from 25 large tertiary hospitals were included, and 302,005 UEBMI inpatients in the 5 pilot reform hospitals were selected as the intervention group, while 705,220 inpatients in other tertiary hospitals were selected as the control group. After exclusion of unqualified samples and 1:1 matching, the final sample size for the next analysis was 520,996.

\section{Propensity score matching (PSM)}

This study performed a 1:1 propensity score-matched analysis stratified by disease groups and years while controlling for age, gender and Charlson Comorbidity Index (CCI). Propensity scores were calculated by logistic regression. The disease groups were defined as the first four International Classification of Diseases tenth version (ICD-10) codes, the smallest unit in this coding category. CCI was calculated according to all secondary diagnoses. In this study, two exclusion criteria were chosen to ensure a smooth match process: first, the sample size in any specific disease group was less than 500; second, only the intervention group or control group were included in any specific disease group. The matching flowchart is shown in Fig. 1. 
Table 1 Description of basic characteristics of the pilot hospitals for each year

\begin{tabular}{|c|c|c|c|c|c|}
\hline & & 2012 & 2013 & 2014 & 2015 \\
\hline N & $=$ & 55,563 & 69,760 & 66,559 & 68,616 \\
\hline Age & Mean (years) & 61.5 & 60.7 & 60.5 & 60.1 \\
\hline \multirow[t]{2}{*}{ Gender } & Female & 25,934 & 33,980 & 31,187 & 32,854 \\
\hline & Male & 29,629 & 35,780 & 35,372 & 35,762 \\
\hline \multirow[t]{3}{*}{$\mathrm{CCl}$} & 0 & 28,008 & 36,670 & 30,149 & 30,458 \\
\hline & 1 & 12,081 & 12,547 & 13,006 & 12,799 \\
\hline & $\geq 2$ & 15,474 & 20,543 & 23,404 & 25,359 \\
\hline \multirow[t]{10}{*}{ Top 10 diagnoses } & Chemotherapy session for neoplasm & 8715 & 9644 & 8976 & 9100 \\
\hline & Unstable angina & 3319 & 3283 & 3849 & 3885 \\
\hline & Cerebral infarction, unspecified & 3424 & 3122 & 3027 & 3032 \\
\hline & Senile cataract, unspecified & 1831 & 4229 & 1775 & 1742 \\
\hline & Type 2 diabetes mellitus with other specified complications & 583 & 1880 & 2070 & 2311 \\
\hline & Atherosclerotic heart disease & 1172 & 1655 & 1421 & 1473 \\
\hline & Unilateral or unspecified inguinal hernia, without obstruction or gangrene & 1353 & 1380 & 1379 & 1411 \\
\hline & Essential (primary) hypertension & 1317 & 1417 & 1398 & 1274 \\
\hline & Palliative care & 1033 & 1414 & 1445 & 1155 \\
\hline & COPD with acute exacerbation, unspecified & 1549 & 1229 & 1220 & 938 \\
\hline
\end{tabular}

\section{Results}

Description of basic characteristics of the pilot hospitals

A total of 520,996 patients were included in this study, with 260,498 patients each included in each of group (the intervention group and the control group). The characteristics of the pilot hospitals and the top 10 disease groups are listed in Table 1.

\section{Annual changes in hospitalization expenses for pilot hospitals}

The total expenditure and other expenditure components of the pilot hospitals are shown in Table 2.

After the zero markup drug policy, for patients in the pilot hospitals, the total expenditures per admission and out-of-pocket costs decreased in year one and increased gradually over the next few years. The total expenditures per admission decreased from 17,140.3 yuan in 2012 to $15,430.1$ yuan in 2013 and then increased to $16,789.8$ yuan in 2015, which was still lower than that before the policy. Out-of-pocket costs demonstrated a similar trend, which went from 4135.5 yuan in 2012 down to 4035.2 yuan in 2013 and then up to 4571.1 yuan in 2015.

Expenditure on drugs revealed a continuous decline over the next four years, while expenditure on medical services had increased growth. Expenditure on drugs reduced from 5811.7 yuan in 2012 to 3903.4 yuan in 2015, and drug expenditure as a share of total expenses per admission decreased from 33.91 to $23.25 \%$. In contrast, expenditure on medical services rose from 1912.4 yuan in 2012 to 2365.5 yuan in 2015, and medical services expenditure as a share of total expenses increased from 11.16 to $14.09 \%$.

Expenditure on medical consumables and diagnostic tests demonstrated the same trend of continuous rise. From 2012 to 2015, expenditure on medical consumables increased from 6033.7 yuan to 6966.3 yuan, an increase 35.20 to $41.49 \%$ of total expenses, and expenditure on diagnostic tests also increased from 2802.2 yuan to 3025.1 yuan, an increase from 16.35 to $18.02 \%$ of total expenses.

\section{Policy impact analysis}

In order to further verify that the changes in expenditure were caused by the impact of the zero markup drug policy, we made a trend comparison with the control group. Since the pilot reform was carried out from September to December 2012 in Beijing, we chose the mean expenditure of the first three quarters of 2012 as the baseline and compared this baseline with the expenditure of every quarter after that (see more in the Appendix 2).

As for total expenditure and out-of-pocket costs, although those expenses decreased at first, the intervention group and control group showed the same trend both in the short-term and the long-term, which indicated that there was no obvious impact of the policy (Fig. 2). To explain why the trend of total expenditure did not change, we further breakdown the expenditure and carried out a specific analysis to see whether the substitution effect of medical consumables or diagnostic tests led to no significant change in the total expenditure in the long- and short-term. 


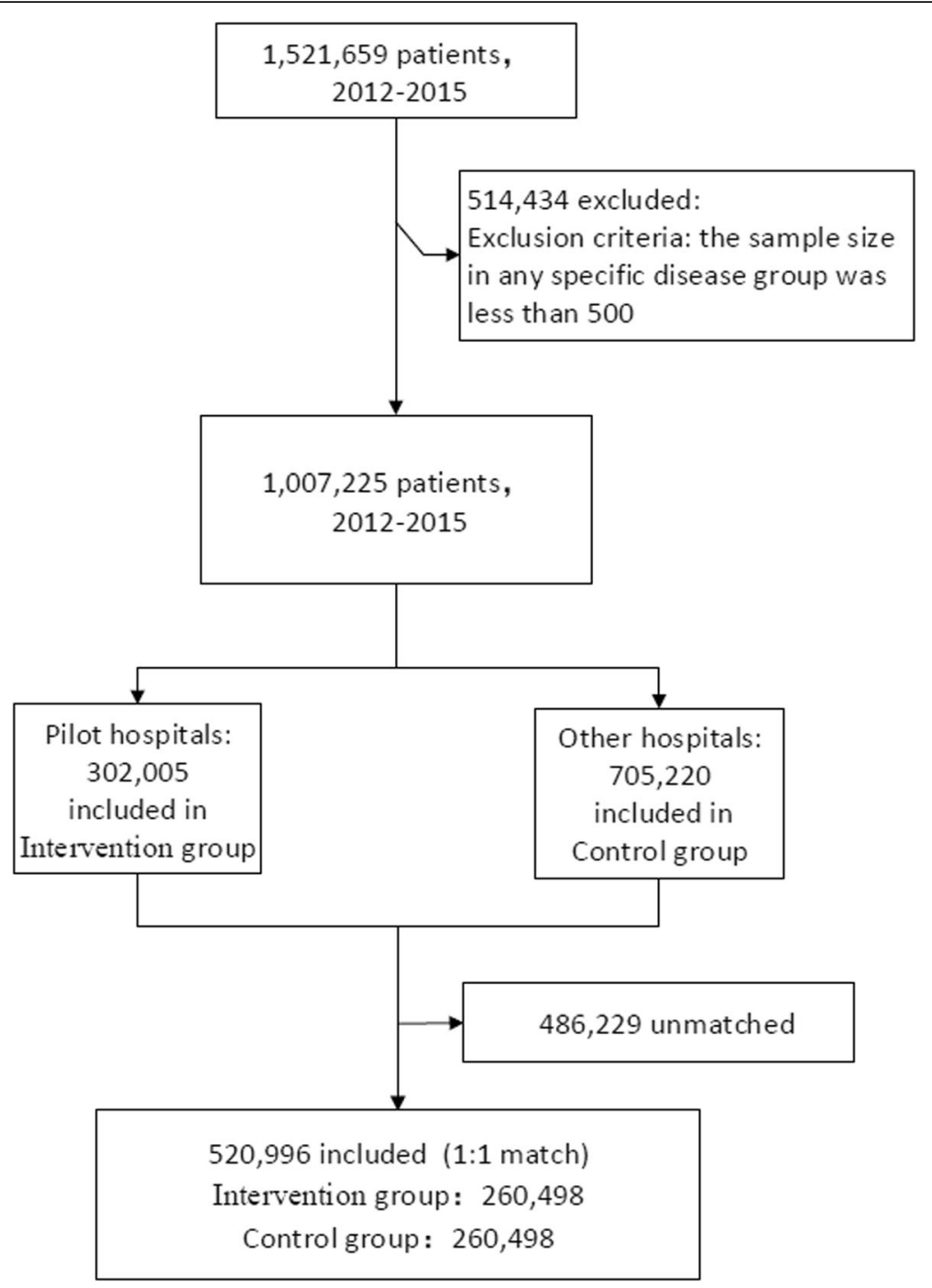

Fig. 1 The flowchart of propensity score-matching

Figure. 3 presents a trend comparison of detailed expenditure between the intervention group and the control group. In the short period after the pilot, the proportion of drug expenditure in the intervention group decreased by $36.9 \%$ from baseline to the end of 2013, which was larger than that in the control group. The proportion of medical services expenditure increased significantly. Contrary to our hypothesis, the proportion of medical consumables and diagnostic tests showed the same trend in both the intervention and control groups, which means that no substitution effect of medical consumables or diagnostic tests was observed in the short term. In the long term, expenditure on drugs remained stable at a low level while expenditure on medical services remained stable at a high level. However, expenditure on medical consumables in the pilot hospitals demonstrated a faster growth rate compared with the control group. Specifically, from the second quarter of 2014, the growth rate of expenditure on consumables increased rapidly. The increase in the second quarter of 2014 was only $4.5 \%$ but $10.8 \%$ in the third quarter and then $17.7 \%$ in the next quarter, while there was only approximately $4-6 \%$ in the control group during the same time. Expenditure on diagnostic tests, nursing services and management services demonstrated little difference between the two groups.

\section{Discussion}

Overall, the zero markup drug policy in Beijing had little impact on the total medical expenditure. Although the total expenditure decreased in the first year, the decline cannot be proven to be caused by the zero markup drug policy. Expenditure on drugs decreased while expenditure on medical services increased in the short term, 
Table 2 Annual hospitalization expenses and details for pilot hospitals

\begin{tabular}{|c|c|c|c|c|c|}
\hline & & 2012 & 2013 & 2014 & 2015 \\
\hline & & Treatment & Treatment & Treatment & Treatment \\
\hline N & $=$ & 55,563 & 69,760 & 66,559 & 68,616 \\
\hline Total expenditures per visit & & $17,140.3$ & $15,430.1$ & $16,650.4$ & $16,789.8$ \\
\hline OOP & & 4135.5 & 4035.2 & 4349.0 & 4571.1 \\
\hline \multirow[t]{2}{*}{ Drugs } & per admission ( $¥)$ & 5811.7 & 4304.0 & 4273.6 & 3903.4 \\
\hline & Share (\%) & $33.91 \%$ & $27.89 \%$ & $25.67 \%$ & $23.25 \%$ \\
\hline \multirow[t]{2}{*}{ Medical services } & per admission ( $¥)$ & 1912.4 & 2213.5 & 2386.8 & 2365.5 \\
\hline & Share (\%) & $11.16 \%$ & $14.35 \%$ & $14.33 \%$ & $14.09 \%$ \\
\hline \multirow[t]{2}{*}{ Medical consumables } & per admission ( $¥)$ & 6033.7 & 5889.0 & 6528.5 & 6966.3 \\
\hline & Share (\%) & $35.20 \%$ & $38.17 \%$ & $39.21 \%$ & $41.49 \%$ \\
\hline \multirow[t]{2}{*}{ Diagnostic tests } & per admission ( $¥)$ & 2802.2 & 2534.2 & 2924.0 & 3025.1 \\
\hline & Share (\%) & $16.35 \%$ & $16.42 \%$ & $17.56 \%$ & $18.02 \%$ \\
\hline \multirow[t]{2}{*}{ Nursing services } & per admission ( $¥)$ & 79.4 & 66.7 & 69.2 & 66.1 \\
\hline & Share (\%) & $0.46 \%$ & $0.43 \%$ & $0.42 \%$ & $0.39 \%$ \\
\hline \multirow[t]{2}{*}{ Management services } & per admission ( $¥)$ & 500.9 & 422.7 & 468.4 & 463.4 \\
\hline & Share (\%) & $2.92 \%$ & $2.74 \%$ & $2.81 \%$ & $2.76 \%$ \\
\hline
\end{tabular}

*Share: share in total expenditures per admission

and both remained stable in the long term. Expenditure on medical consumables in the pilot hospitals maintained the same trend as the control group in the first year but demonstrated a higher growth rate than that in the control group over the next three years. Expenditure on diagnostic tests, nursing services and management services showed the same trend between the two groups.

This study presented short-term results similar to other studies and filled the research gap on the longterm unintended effect on medical consumables and diagnostic tests $(18,21,22)$. Studies on county-level hospitals in China have demonstrated the failure to reduce total expenditure and have even indicated an unintended increase. The substitution effect of medical consumables and diagnostic tests is the focus of this study. Due to physician agency theory, the removal of drug markups may result in unintended changes in supplier behaviour, such as the increased consumption of medical consumables or diagnostic tests (23). However, the results for changes in expenditure on medical consumables were varied. One study that analysed county-level public hospitals in Shandong province in China noted that no expenditure transfer from drugs to medical consumables or diagnostic tests was observed due to the removal of drug markups (20). We think the reasons for inconsistent conclusions came from three aspects. First, it is difficult to obtain representative results by analysing small sample data and a single disease group. In this study, all

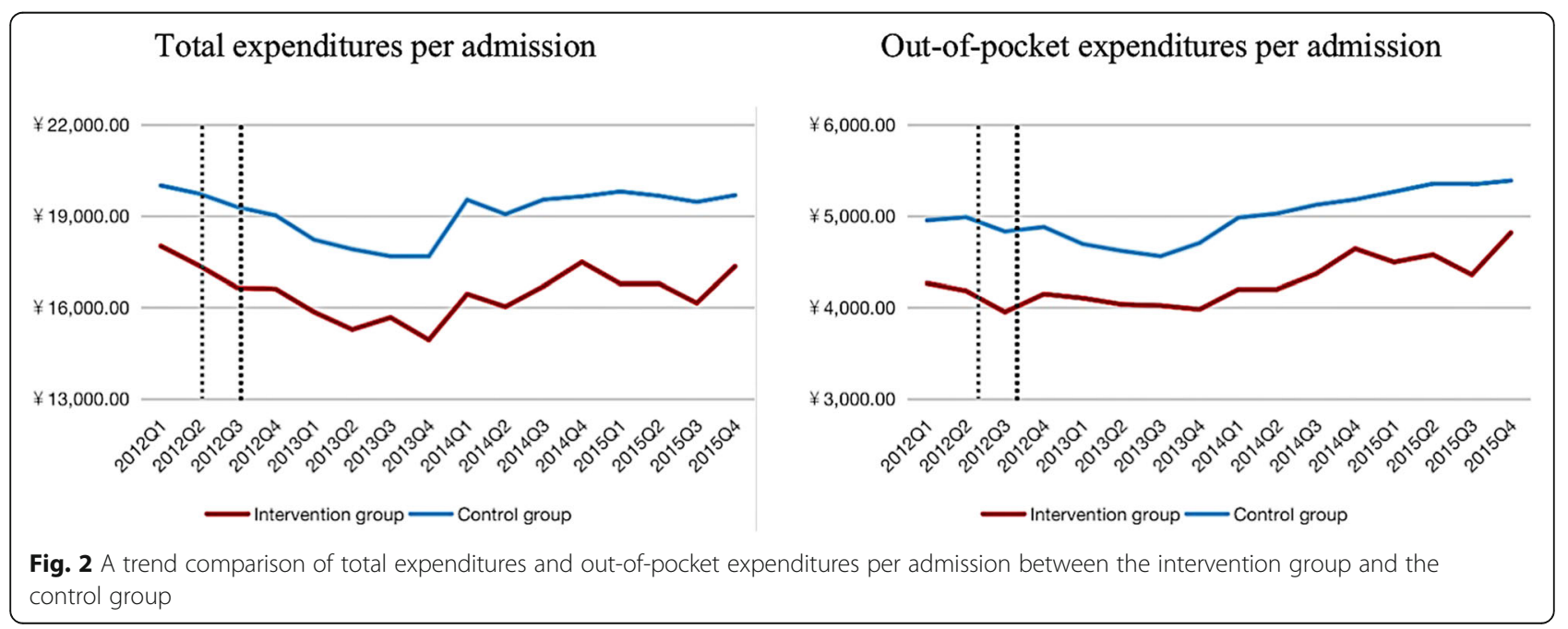




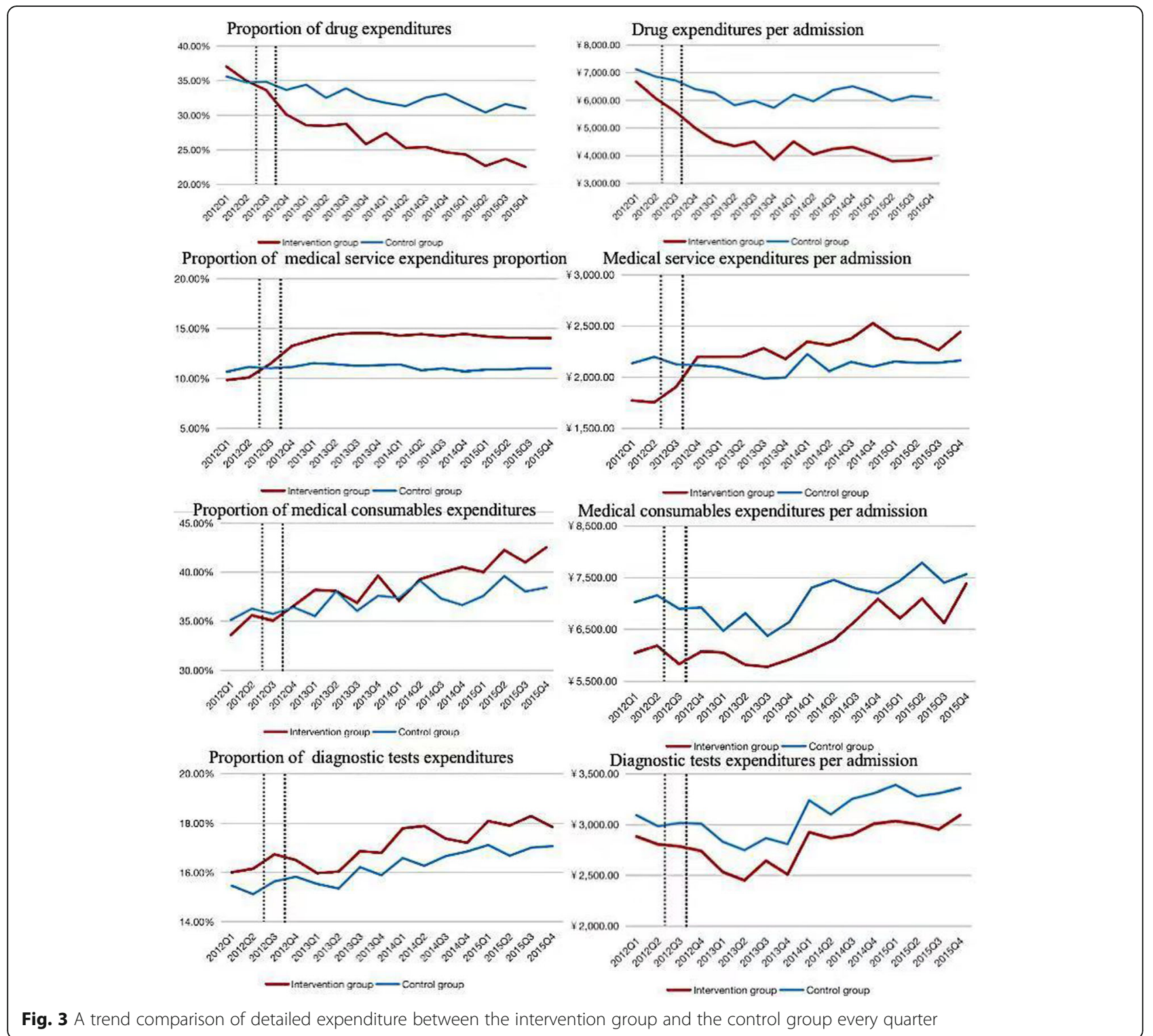

disease groups were included. Next, the conclusion can be different without comparison with the control group. Third, short-term research cannot reveal the unintended impact of the policy because of the Hawthorne effect. Our study found that expenditure on medical consumables indeed rose in the long term, and there was an obvious difference in this trend when compared with the control group, which was consistent with our assumption.

Although this study indicated the short-term and long-term effects of zero markup drug policy, the following limitations remained. The data from the Beijing UEBMI database lacked specific lists of drug consumption, which limited further analysis of drug usage, especially for comparisons between high-value drugs and low-value drugs. More detailed consumptions data are needed to evaluate the impact of the zero markup drug policy.

Given that all unintended impacts, such as the substitution effect of medical consumables and diagnostic tests, are due to the fee-for-service payment system, the further policy recommendation is to be more focused on the reforms of payment system. In the future, payment system reforms can play a more important role in controlling drug consumption and expenditure (24). For example, the reform pilot in Ningxia province in China affected the behaviour of doctors by introducing a capitation budget with pay-for-performance and thus reduced the use of antibiotics and the total expenditure significantly (25). More incentive reforms were needed to constrain doctors from over-prescription of both drugs and medical consumables. 


\section{Appendix 1}

Table 3 CPI adjusted

\begin{tabular}{llll}
\hline year & unadjusted & adjusted(2012 baseline) & CPI \%, The year-earlier index was 100 \\
\hline 2012 & Y1 & Y1/100\% & $/$ \\
2013 & Y2 & $Y 2 / 103.3 \%$ & 103.3 \\
2014 & Y3 & $Y 3 / 101.6 \% / 103.3 \%$ & 101.6 \\
2015 & Y4 & $Y 3 / 101.8 \% / 101.6 \% / 103.3 \%$ & 101.8
\end{tabular}

All expenditure variables are converted to 2012 using the Consumer Price Index

\section{Appendix 2}

Table 4 Expenditure changes of pilot hospital every quarter after baseline

\begin{tabular}{lllllllll}
\hline & $\begin{array}{l}\text { Total expenditures per } \\
\text { visit }\end{array}$ & OOP & Drugs & $\begin{array}{l}\text { Medical } \\
\text { services }\end{array}$ & $\begin{array}{l}\text { Medical } \\
\text { consumables }\end{array}$ & $\begin{array}{l}\text { Diagnostic } \\
\text { tests }\end{array}$ & $\begin{array}{l}\text { Nursing } \\
\text { services }\end{array}$ & $\begin{array}{l}\text { Management } \\
\text { services }\end{array}$ \\
\hline 2012Q1- & Reference & Reference & Reference & Reference & Reference & Reference & Reference & Reference \\
2012Q4 & $-4.2 \%$ & $0.4 \%$ & $-18.1 \%$ & $21.4 \%$ & $0.9 \%$ & $-3.0 \%$ & $-3.4 \%$ & $3.9 \%$ \\
$2013 \mathrm{Q} 1$ & $-8.6 \%$ & $-0.7 \%$ & $-25.9 \%$ & $21.5 \%$ & $0.5 \%$ & $-10.3 \%$ & $-15.5 \%$ & $-4.1 \%$ \\
$2013 \mathrm{Q} 2$ & $-11.9 \%$ & $-2.4 \%$ & $-28.9 \%$ & $21.4 \%$ & $-3.4 \%$ & $-13.3 \%$ & $-17.5 \%$ & $-18.6 \%$ \\
$2013 \mathrm{Q} 3$ & $-9.6 \%$ & $-2.7 \%$ & $-26.2 \%$ & $26.0 \%$ & $-4.0 \%$ & $-6.4 \%$ & $-13.4 \%$ & $-20.1 \%$ \\
$2013 \mathrm{Q} 4$ & $-13.9 \%$ & $-3.7 \%$ & $-36.9 \%$ & $20.2 \%$ & $-1.7 \%$ & $-11.2 \%$ & $-20.6 \%$ & $-16.2 \%$ \\
$2014 \mathrm{Q} 1$ & $-5.2 \%$ & $1.6 \%$ & $-26.2 \%$ & $29.6 \%$ & $1.2 \%$ & $3.5 \%$ & $-12.7 \%$ & $0.6 \%$ \\
$2014 \mathrm{Q} 2$ & $-7.6 \%$ & $1.7 \%$ & $-33.8 \%$ & $27.6 \%$ & $4.5 \%$ & $1.5 \%$ & $-15.6 \%$ & $-10.8 \%$ \\
$2014 \mathrm{Q} 3$ & $-3.7 \%$ & $5.7 \%$ & $-30.6 \%$ & $31.2 \%$ & $10.8 \%$ & $2.7 \%$ & $-15.3 \%$ & $-10.3 \%$ \\
$2014 \mathrm{Q} 4$ & $0.9 \%$ & $12.3 \%$ & $-29.5 \%$ & $39.6 \%$ & $17.7 \%$ & $6.5 \%$ & $-10.8 \%$ & $-1.7 \%$ \\
$2015 \mathrm{Q} 1$ & $-3.2 \%$ & $8.8 \%$ & $-33.3 \%$ & $31.6 \%$ & $11.5 \%$ & $7.4 \%$ & $-16.7 \%$ & $2.1 \%$ \\
$2015 \mathrm{Q} 2$ & $-3.2 \%$ & $10.7 \%$ & $-37.8 \%$ & $30.6 \%$ & $17.8 \%$ & $6.4 \%$ & $-17.6 \%$ & $-7.5 \%$ \\
$2015 \mathrm{Q} 3$ & $-6.9 \%$ & $5.4 \%$ & $-37.4 \%$ & $25.1 \%$ & $10.0 \%$ & $4.6 \%$ & $-17.8 \%$ & $-14.9 \%$ \\
$2015 \mathrm{Q} 4$ & $0.0 \%$ & $16.6 \%$ & $-36.1 \%$ & $34.8 \%$ & $22.6 \%$ & $9.6 \%$ & $-17.9 \%$ & $-6.9 \%$ \\
\hline
\end{tabular}




\section{Conclusions}

After the zero markup drug policy, expenditure on drugs revealed a continuous decline. However, a significant substitution effect of medical consumables was first observed in the third quarter of 2014, which undermined the impact of the policy. This filled the research gap on the long-term unintended effect on medical consumables and diagnostic tests. In the long-term, the intervention group and control group demonstrated the same trend.

\section{Abbreviations}

CCl: Charlson Comorbidity Index; ICD: International Classification of Diseases; OECD: Organisation for Economic Co-operation and Development; OOP: Out-of-pocket; PSM: Propensity score-matching; UEBMI: Urban Employee Basic Medical Insurance,

\section{Acknowledgements}

Not Applicable.

\section{Provenance and peer review}

Not commissioned; externally peer reviewed.

\section{Authors' contributions}

JZ led the design of the study and drafted the manuscript. XC and HF participated in interpretation of results and drafting of the manuscript. ML contributed to data acquisition and participated in paper writing. WJ guided $\mathrm{JZ}$ in the design of the study and contributed to writing of the manuscript. All authors have read and approved the final draft.

\section{Funding}

This study was funded by China Medical Board (grant number: 16-259). The funding source did not play a role in the design and conduct of the study; collection, management, analysis, and interpretation of data; preparation in writing or submitting the manuscript.

\section{Availability of data and materials}

The datasets generated during the current study are not publicly available in accordance with the project agreement, but are available from the corresponding author at jianweiyan@bjmu.edu.cn on reasonable request.

\section{Ethics approval and consent to participate}

This study was approved by Peking University Institutional Review Board (IRB number: IRB00001052-18005). No patients were involved in developing outcome measures and no analyses included any identifiable patient data.

\section{Consent for publication}

Not required.

\section{Competing interests}

None declared.

\section{Author details}

'Department of Health Policy and Management, School of Public Health, Peking University Health Science Center, Beijing, China. ${ }^{2}$ Department of Medical Informatics, School of Basic Medicine, Peking University Health Science Center, Beijing, China.

Received: 7 October 2019 Accepted: 20 November 2019 Published online: 29 November 2019

\section{References}

1. Shanlian H, Shenglan T, Yuanli L, Yuxin Z, Maria-Luisa E, David DF. Reform of how health care is paid for in China: challenges and opportunities. Lancet. 2008;372(9652):1846-53.
2. Fan $\mathrm{V}$, Savedoff WD. The health financing transition: a conceptual framework and empirical evidence. Social science \& medicine (1982). 2014; 105:112-21.

3. Le Gales C. Evolution, determinants and regulation of drug expenditures in France. Med Sci: M/S. 2018;34(1):83-6.

4. O'Neill P, Mestre-Ferrandiz J, Puig-Peiro R, Sussex J. Projecting expenditure on medicines in the UK NHS. PharmacoEcon. 2013:31(10):933-57.

5. Moreno-Serra R. The impact of cost-containment policies on health expenditure. 2014

6. Yip W, Hsiao WC. The Chinese health system at a crossroads. Health Aff (Project Hope). 2008:27(2):460-8.

7. Fu H, Li L, Li M, Yang C, Hsiao W. An evaluation of systemic reforms of public hospitals: the Sanming model in China. Health Policy Plan. 2017;32(8): 1135-45.

8. Yip W, Hsiao W. China's health care reform: a tentative assessment. China Econ Rev. 2009;20(4):613-9.

9. David B, William H. Privatization and its discontents--the evolving Chinese health care system. N Engl J Med. 2005;353(11):1165-70.

10. Currie J, Lin W, Meng J. Addressing antibiotic abuse in China: an experimental audit study. J Dev Econ. 2014:110:39-51.

11. Li Y, Xu J, Wang F, Wang B, Liu L, Hou W, et al. Overprescribing in China, driven by financial incentives, results in very high use of antibiotics, injections, and corticosteroids. Health Aff (Project Hope). 2012;31(5):1075-82

12. Yang G, Kong L, Zhao W, Wan X, Zhai Y, Chen LC, et al. Emergence of chronic non-communicable diseases in China. Lancet. 2008;372(9650): 1697-705.

13. Chen Z. Launch of the health-care reform plan in China. Lancet. 2009; 373(9672):1322-4

14. Liu Q, Wang B, Kong Y, Cheng KK. China's primary health-care reform. Lancet. 2011;377(9783):2064-6.

15. Yip CM, Hsiao W, Meng Q, Chen W, Sun X. Realignment of incentives for health-care providers in China. Lancet. 2010;375(9720):1120-30

16. Barber SL, Borowitz M, Bekedam H, Ma J. The hospital of the future in China: China's reform of public hospitals and trends from industrialized countries. Health Policy Plan. 2014:29(3):367-78.

17. McGuire TG, Pauly MV. Physician response to fee changes with multiple payers. J Health Econ. 1991:10(4):385-410.

18. Fu H, Li L, Yip W. Intended and unintended impacts of price changes for drugs and medical services: Evidence from China. Social science \& medicine (1982). 2018;211:114-22.

19. Yi H, Miller G, Zhang L, Li S, Rozelle S. Intended and unintended consequences of China's zero markup drug policy. Health Aff (Project Hope). 2015;34(8):1391-8.

20. Ma G, Ma A, Yin A, Sheng $H$. Research on the influences of county-leve hospital comprehensive reform policy on hospital operation. Chinese Health Econ. 2014;1:17-20.

21. Zhou Z, Su Y, Campbell B, Zhou Z, Gao J, Yu Q, et al. The financial impact of the 'zero-markup policy for essential drugs' on patients in county hospitals in western rural China. PLoS One. 2015;10(3):e0121630.

22. Xiao Y, Zhao K, Bishai DM, Peters DH. Essential drugs policy in three rural counties in China: what does a complexity lens add? Social science \& medicine (1982). 2013;93:220-8.

23. Liu X, Liu Y, Chen N. The Chinese experience of hospital price regulation. Health Policy Plan. 2000;15(2):157-63.

24. Yip WC, Hsiao WC, Chen W, Hu S, Ma J, Maynard A. Early appraisal of China's huge and complex health-care reforms. Lancet. 2012;379(9818) 833-42.

25. Powell-Jackson T, Yip WC, Han W. Realigning demand and supply side incentives to improve primary health care seeking in rural China. Health Econ. 2015;24(6):755-72

\section{Publisher's Note}

Springer Nature remains neutral with regard to jurisdictional claims in published maps and institutional affiliations. 